http://jmscr.igmpublication.org/home/

ISSN (e)-2347-176x ISSN (p) 2455-0450

crossref DOI: https://dx.doi.org/10.18535/jmscr/v7i10.132

Journal Of Medical Science And Clinical Research

IGM Publication

An Official Publication of IGM Publication

\title{
Maternal factors Associated with Meconium Staining of Amniotic Fluid in Labour - A Case Control Study
}

Authors

\section{Dr Anju SS ${ }^{1}$, Dr Geetha $\mathrm{M} \mathrm{I}^{2 *}$, Dr Sreekumari $\mathbf{R}^{3}$}

${ }^{1}$ Post Graduate student, Dept. of O \& G, SAT Hospital, Govt. Medical College, Trivandrum

${ }^{2}$ Associate Professor, Dept. of O \& G, SAT Hospital, Govt. Medical College, Trivandrum.

${ }^{3}$ Professor, Dept. of OBG, Govt. Medical College, Konni

*Corresponding Author

Dr Geetha M I

Associate Professor, Dept. of O \& G, SAT Hospital, Govt. Medical College, Trivandrum, India

\begin{abstract}
Objective: Meconium aspiration syndrome (MAS) is a life threatening respiratory disease in infants born through meconium stained amniotic fluid (MSAF). The purpose of this study is to determine thematernal risk factors for thick MSAF in labour and thus to identify the fetus and new born at risk of MAS and for possible early interventions.

Methods: Case Control study.

Results: Of the thick meconium stained amniotic fluidcases in labour 37.8\% had induced labour. $31 \%$ belong to very poor socio economic status compared to $16 \%$ of control group. The maternal factors associated with thick MSAF were Hypertension 12.2\%, fever in third trimester 10\%,Bronchial asthma 10\%, Diabetes 8\%, and obstetric factors were Postdated Pregnancies 15\%, Gestational hypertension $12.2 \%$, Previous cesarean $8.9 \%$, GDM 7.8\%, Anemia $7.2 \%$.

Conclusion: The maternal factors for MSAF according to the study were poor socio economic and educational status of mother. Maternal medical and obstetric factors like Hypertension, postdated pregnancies, Diabetes Mellitus, fever in $3^{\text {rd }}$ trimester, Induction of Labour, Gestational Hypertension, Previous Cesarean, GDM, Anemia etc.

Keywords: Meconium stained amniotic fluid, Meconium aspiration syndrome, Abnormal doppler.
\end{abstract}

\section{Introduction}

Meconium stained amniotic fluid (MSAF) is an alarming sign of fetal compromise and may be associated with a poor perinatal outcome. Incidence of MSAF, ranges from 7 to $22 \%{ }^{1}$ while meconium aspiration syndrome occurs in approximately $5 \%$ of all cases of MSAF. Meconium is the first intestinal discharge from new born - a viscous, dark green substancecomposed of intestinal epithelial cells, lanugo hair, mucus, and intestinal secretions.
Meconium is sterile and does not contain bacteria which is the primary factor that differentiates it from stool. Intra uterine distress can cause passage of meconium in to the amniotic fluid. ${ }^{2}$ Factors that promote passage in utero includes maternal hypertension, Diabetes, Maternal infections, Drug abuse, Asthma and Heart diseases and obstetric complications like GHT - pre eclampsia, post dated pregnancies, GDM, intrapartum infections etc. ${ }^{3}$ 
Many variables including FHR abnormalities, thick MSAF, low APGAR score has been associated with higher risk of meconium aspiration syndrome (MAS). There is some interaction between meconium and cardiotocograph pattern such that if CTG is abnormal the presence of meconium is associated with significantly higher chance of baby being acidotic, born in poor condition and need resuscitation.

\section{Materials and Methods}

Study Design- This is a case control study for one year period

This Study is undertaken to find out the maternal factors associated with thick meconium staining of AF, and thus to identify the fetus and newborn at risk of MAS for possible early intervention.

\section{Objective of the Study}

To find out the factors associated with thick meconium staining of amniotic fluid in labour.

Specific Objectives were to find out

1) The influence of various medical and obstetric factors associated with MSAF.

2) The role of induction of labour in MSAF

3) The socio-demographic distribution of obstetric patients and its influence on MSAF.

\section{Sampling Size}

The sample size has been calculated using the formula:

$$
\mathrm{E}=\mathrm{Z} \frac{a}{2}, \frac{\partial}{\sqrt{n}}
$$

Where $\mathrm{Z} \frac{a}{2}$ is the critical value; is the population standard deviation and ' $n$ ' is the sample size. $E$ is the maximum difference between observed sample mean, $x$ and true population mean,

Using this formula, sample size for cases was calculated to be 173. Among 196 cases of thick MSAF, after exclusion, 180 cases were taken up for study.

\section{Technique}

Cases: Patients in labour with thick meconium stained amniotic fluid detected at the time of or after rupture of membrances.

Control: Patients in labour with clear amniotic fluid at the time of rupture of membrance - the control was selected from those cases with clear liquor which comes next to each meconium case in the labour room register at random.

\section{Statistical Analysis}

Data were analyzed using computer software, Statistical Package for Social Sciences (SPSS) version 10. Data are expressed in its frequency and percentage as well as mean and standard deviation. To elucidate the associations and comparisons between different parameters, Chi square $\left(\mathrm{x}^{2}\right)$ test was used as nonparametric test. Multivariate logistic regression analysis was performed to assess the risk factors (Odds ratio) of different factors for each group. For all statistical evaluations, a two-tailed probability of value of $<0.05$ was considered significant

\section{Observation and Results}

In the study group, $31 \%$ belonged to very low socioeconomic status, compared to $16 \%$ of among control group.

Table 1: Distribution according to place of residence

\begin{tabular}{|l|c|c|}
\hline Residence & Cases & Control \\
\hline Rural & 34 & 49 \\
& $19.00 \%$ & $26.70 \%$ \\
\hline Urban & 36 & 49 \\
& $20.00 \%$ & $26.70 \%$ \\
\hline Semiurban & 110 & 84 \\
& $61.00 \%$ & $46.70 \%$ \\
\hline
\end{tabular}

Table 2 Distribution based on socioeconomic status

\begin{tabular}{|l|c|c|}
\hline Income & Cases & Control \\
\hline$\leq$ Rs. 1000 & 56 & 29 \\
& $31.11 \%$ & $15.93 \%$ \\
\hline $1000-3000$ & 91 & 113 \\
& $50.56 \%$ & $62.08 \%$ \\
\hline$\geq 3000$ & 33 & 40 \\
& $18.33 \%$ & $21.98 \%$ \\
\hline
\end{tabular}

Chi square $=13.082 ; \mathrm{p}=0.004(<0.01)$

In the study group, $2.78 \%$ were illiterate compared to $0.55 \%$ of controls 


\section{Medical Problem}

In this study, Maternal Hypertension10\%, diabetes mellitus $8 \%$, Jaundice $6 \%$, bronchial asthma10\%, maternal fever in third trimester $10 \%$, thyroid disease $2 \%$ and heart disease $4 \%$ were more in the study group.

Table 3 Maternal Medical conditions complicating pregnancy

\begin{tabular}{|l|c|c|c|}
\hline Medical Problems & Cases & Control & P value * \\
\hline Hypertension & $\begin{array}{c}18 \\
10.00 \%\end{array}$ & $\begin{array}{c}17 \\
9.30 \%\end{array}$ & $\begin{array}{c}0.845 \\
(>0.05)\end{array}$ \\
\hline Diabetes Mellitus & 14 & 2 & 0.002 \\
& $8.00 \%$ & $1.30 \%$ & $(<0.01)$ \\
\hline Jaundice & 10 & 7 & 0.442 \\
& $6.00 \%$ & $4.00 \%$ & $(>0.05)$ \\
\hline Asthma Heart & 18 & - & 0.0 \\
& $10.00 \%$ & & $(<0.001)$ \\
\hline $\begin{array}{l}\text { History of Fever in } \\
\text { 4rd Trimester }\end{array}$ & $10.00 \%$ & $1.30 \%$ & $\begin{array}{c}0.0 \\
(<0.001)\end{array}$ \\
\hline Thyroid Disease & 4 & - & 0.043 \\
& $2.00 \%$ & - & 0.043 \\
& 4 & - & 0.043 \\
\hline $\begin{array}{l}\text { Rheumatic Maternal } \\
\text { Disease }\end{array}$ & $9.00 \%$ & & $(<0.05)$ \\
\hline $\begin{array}{l}\text { Congenital Hisease } \\
\text { Dicar }\end{array}$ & $50.00 \%$ & $84.00 \%$ & - \\
\hline $\begin{array}{l}\text { No } \\
\text { complications }\end{array}$ & & & \\
\hline
\end{tabular}

\section{Obstetrical Complications}

Table 4 Association between obstetrical complications and MSAF

\begin{tabular}{|l|c|c|c|}
\hline Obstetric Problems & Cases & Control & P value \\
\hline GHT & $\begin{array}{c}22 \\
12.20 \%\end{array}$ & $\begin{array}{c}12 \\
6.60 \%\end{array}$ & $\begin{array}{c}0.07 \\
(>0.05)\end{array}$ \\
\hline Previous CS & 16 & 2 & 0.001 \\
& $8.90 \%$ & $1.10 \%$ & $(<0.01)$ \\
\hline GDM & 14 & 2 & 0.002 \\
& $7.80 \%$ & $1.10 \%$ & $(<0.01)$ \\
\hline Anaemia & 13 & - & 0.0 \\
& $7.20 \%$ & & $(<0.001)$ \\
\hline HELLP & 2 & - & 0.247 \\
& $1.11 \%$ & & $(>0.05)$ \\
\hline No Obstetric & 113 & 166 & - \\
Complications & $62.80 \%$ & $91.20 \%$ & \\
\hline
\end{tabular}

Chi square $=21.621 ; \mathrm{p}=0.003(<0.01)$

Gestational hypertension $12 \%$, previous CS $8.9 \%$, gestational diabetes mellitus $7.8 \%$, Anaemia $7.2 \%$, HELLP $1.1 \%$, are more among study group.
Fig. 12. Distribution of obstetric problems in cases

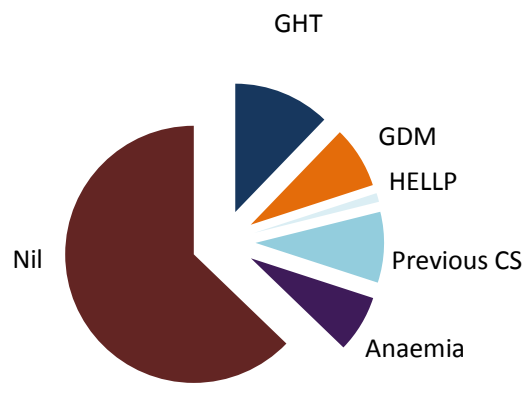

\section{Doppler}

Table 5 Distribution according to Doppler

\begin{tabular}{|l|c|c|}
\hline Doppler & Cases & Control \\
\hline Abnormal & 112 & 17 \\
& $62.00 \%$ & $9.33 \%$ \\
\hline Normal & 68 & 165 \\
& $38.00 \%$ & $90.67 \%$ \\
\hline
\end{tabular}

Chi square $=110.336 ; \mathrm{p}=0.0(<0.001)$

$62 \%$ cases had abnormal Doppler whereas only $7 \%$ among controls had a Doppler abnormality.

Table No 6 Association between gestational age and MSAF

\begin{tabular}{|l|c|c|}
\hline $\begin{array}{l}\text { Gestational } \\
\text { Age }\end{array}$ & Cases & Control \\
\hline $38-40$ Weeks & 153 & 182 \\
& $85.00 \%$ & $100 \%$ \\
\hline Past Date & 27 & - \\
& $15.00 \%$ & \\
\hline
\end{tabular}

Chi square $=12.305 ; \mathrm{p}=0.0(<0.001)$

\section{Mode of Induction}

Table 7 Association between mode of induction and MSAF

\begin{tabular}{|l|c|c|c|}
\hline $\begin{array}{l}\text { Mode of } \\
\text { Induction }\end{array}$ & Cases & Control & P value \\
\hline PGE1 & 7 & 3 & 0.210 \\
& $10.30 \%$ & $8.80 \%$ & $(>0.05)$ \\
\hline PGE2 & 22 & 7 & 0.004 \\
& $32.40 \%$ & $20.60 \%$ & $(<0.01)$ \\
\hline ARM & 21 & 14 & 0.210 \\
& $30.90 \%$ & $41.20 \%$ & $(>0.05)$ \\
\hline Oxytocin & 18 & 10 & 0.119 \\
& $26.50 \%$ & $29.40 \%$ & $(>0.05)$ \\
\hline
\end{tabular}

Chi square $=7,891 ; \mathrm{p}=0.036(<0.05)$ 


\section{Type of Labour}

Table 8 Association between type of labour and MSAF

\begin{tabular}{|l|c|c|}
\hline Type of labour & Cases & Control \\
\hline Spontaneous & 96 & 124 \\
& $53.30 \%$ & $68.10 \%$ \\
\hline Inducced & 68 & 34 \\
& $37.80 \%$ & $18.70 \%$ \\
\hline Elective LSCS & 16 & 24 \\
& $8.90 \%$ & $13.20 \%$ \\
\hline
\end{tabular}

Chi square $=8,341 ; \mathrm{p}=0.039(<0.05)$

$37.8 \%$ of cases were induced, (Control $18.7 \%$ )

In the study group, 5.3\% had normal labour while $46.7 \%$ had abnormal labour (37.8\% inductions and $8.9 \%$ elective LSCS). In the control group $68.1 \%$ had normal labour and $31.9 \%$ had abnormal labour (18.7\% inductions and $13.2 \%$ elective LSCS)

$87.8 \%$ of cases had ROM - delivery interval of $<24 \mathrm{hrs}$, while $1.1 \%$ had delivery $24 \mathrm{hrs}$ after ROM. In the control group, $85.2 \%$ had ROM delivery interval $<24 \mathrm{hrs}$, and no cases after 24 hrs. In the second stage, $11.1 \%$ of cases had ROM, while $14.8 \%$ controls had ROM.

\section{Discussion}

In this study group, $19 \%$ belonged to rural areas, $20 \%$ to urban areas and $61 \%$ to semiurban areas. This is not statistically significant.

The relation between SES and MSAF is tested statistically using chi-square test and found that the difference in statistically significant ${ }^{7}(31 \%$ belonged to very low socio economic group).We can state poor socioeconomic status of the mother is associated with poor perinatal outcome. Several previous studies in this field had similar findings.

In the study group, $2.78 \%$ were illiterate compared to $0.55 \%$ of control. This was found to be statistically significant. This may be due to several factors. Illiterate mothers usually come under low socioeconomic status, so malnutrition and anemia and ill health prevail in such populations.

Maternal medical complications like hypertension (10.\%), diabetes mellitus (8\%), jaundice (6\%), bronchial asthma (10\%), fever (10\%), thyroid disease $(2 \%)$, rheumatic and congenital heart disease (4\%)were more among study group compared to control group. The relation between the medical complication and MSAF were tested statistically and found to be statistically significant. This means that those cases with medical complications are at a higher risk for MSAF, this has been proved in several studies.

Obstetric complications like Gestational HTN (12\%), previous CS(8.9\%), gestational DM (7.8\%), anaemia (7.2\%), HELLP $(1.1 \%)$ were more among study group compared to control group that is statistically significant.

Gestational hypertension i.e., when diastolic BP is elevated above $90 \mathrm{~mm}$ of $\mathrm{Hg}$, significantly worsens the perinatal outcome ${ }^{5}$. Gestational diabetes mellitus was significantly associated with MSAF. Anemia is highly significant in causing intrapartm fetal distress.

$62 \%$ cases had abnormal Doppler whereas only $7 \%$ among control had a Doppler abnormality. This was found to be statistically significant. Thus antenatal scans showing a compromised fetus definitely has a risky intrapartum period and were more prone for hypoxia and acidosis.

$15 \%$ of cases delivered past date while there were no cases of past date in the control group. This difference was statistically significant. In a study it is seen that there in increased risk of perinatal mortality in post term compared to term births. It confirms the observation that post term infants experience more morbidity and mortality than term infants prompting routine antenatal testing and active management of post dated pregnancies. A study by Maymon E et al also shows that MSAF increased with gestational age ${ }^{6}$.

In the study group, $53.3 \%$ had normal labour while $46.7 \%$ had abnormal labour and was found to be statistically significant. The inductions were high among study group - this is also due to various complications of pregnancy necessitating pregnancy termination which explains the higher incidence of meconium staining.

$37.8 \%$ of cases were induced, while $18.7 \%$ of controls had induced labour. Of the cases, $10 \%$ 
were induced with PGE1, 32.3\% with PGE2 30\% with amniotomy, and $27.7 \%$ with oxytocin. Induction with PGE1, ARM or oxytocin was not found to be statistically significant on analysis whereas induction with PGE2 was found to be highly significant. $12.2 \%$ of cases had maternal fever intrapartum while $6.6 \%$ of control group had maternal fever. Of these, all cases and controls delivered in $6 \mathrm{hrs}$. This is statistically significant.

\section{Conclusion}

Thick meconium staining of amniotic fluid is associated with more morbidity and mortality. This study aimed to identify the maternal factors of MSAF with an intention to reduce their incidence in future cases.

The maternal factors associated with MSAF according to this study were poor socioeconomic and educational status of mother, maternal medical complications like hypertension, DM, maternal infections, bronchial asthma, heart diseases and obstetric complications like post dated pregnancies, gestational hypertension, GDM, doppler abnormalities, induction of labour especially with PGE2 and intrapartum maternal fever.

So based on this study, the suggestions that put forward to better the neonatal outcome are

$>$ Identify all maternal medical and obstetric complications at the earliest and start treatment, foresee and prevent complications and plan judicious, timely termination of pregnancy.

$>$ Improve the socioeconomic and educational status of the female population

$>$ Avoid pregnancies towards the tail of reproductive career, complete families earlier.

Antenatal care, a preventive science, should be meticulous in identifying the high risk cases and early referral to a well equipped hospital is all the most important.
$>$ Intense antepartum surveillance and timely termination of pregnancy for abnormal Doppler velocimetry.

\section{References}

1. Khatun MH, Arzu J, Haque E, Kamal MA, Al Mamun MA, Khan MF, Hoque MM. Fetal outcome in deliveries with meconium stained liquor. Bangladesh Journal of Child Health. 2009;33(2):41-5

2. Ouladsahebmadarek E, Hoseinian $\mathrm{MH}$, Hamdi K, Ghojazadeh M. Perinatal outcome in relation to mode of delivery in MeconiumStained Neonates Pak J med sci2012;28(1):13-16.

3. Curtis PD, Matthews TG, Clarke TA. Neonatal seizures: McIntosh N, Helm P. Smyth R. Meconium Aspiration Syndrome, The Newborn In: Forfar and Arneils textbook of pediatrics. 2004:185-6.

4. Mundhra R, Agarwal M. Fetal outcome in meconium stained deliveries. Journal of clinical and diagnostic research: JCDR. 2013 Dec;7(12):2874.

5. Addisu D, Asres A, Gedefaw G, Asmer S. Prevalence of meconium stained amniotic fluid and its associated factors among women who gave birth at term in FelegeHiwot comprehensive specialized referral hospital, North West Ethiopia: a facility based crosssectional study. BMC pregnancy and childbirth. 2018 Dec;18(1):429.

6. Maymon E, Chaim W, Furman B, Ghezzi F, Vardi IS, Mazor M. Meconium stained amniotic fluid in very low risk pregnancies at term gestation. European Journal of Obstetrics \& Gynecology and Reproductive Biology. 1998 Oct 1;80(2):169-73.

7. Rathore AM, Ramji S, Devi CB, Saini S, Manaktala U, Batra S. Fetal scalp stimulation test: An adjunct to intermittent auscultation in non- reassuring fetal status during labor. Journal of Obstetrics and Gynaecology Research. 2011 Jul;37(7):819-24. 